\title{
CFD Modelling of Liquid Metal Flow and Heat Transfer in Blast Furnace Hearth
}

\author{
Bao-Yu GUO, ${ }^{1)}$ Daniel MALDONADO, ${ }^{2)}$ Paul ZULLI' ${ }^{21}$ and Ai-Bing YU ${ }^{11}$ \\ 1) Laboratory for Simulation and Modelling of Particulate Systems, School of Materials Science and Engineering, University of \\ New South Wales, Sydney, NSW 2052, Australia. $\quad$ 2) BlueScope Steel Research, Port Kembla, NSW 2505, Australia.
}

(Received on July 3, 2008; accepted on September 2, 2008)

\begin{abstract}
An in-depth understanding of the liquid metal flow and heat transfer is essential in order to identify the key mechanisms for the hearth erosion of a blast furnace. In this study, a comprehensive computational fluid dynamics model is described which predicts the flow and temperature distributions of liquid iron in blast furnace hearth, and the temperature distribution in the refractories. The new model addresses conjugate heat transfer, natural convection and turbulent flow through porous media, with its main features including improved transport equations (a modified $k-\varepsilon$ turbulence model and thermal dispersion term) and a three-dimensional, high-resolution grid. The new turbulence model and terms take account of the effect of microscopic flows around coke particles and allow unified treatment of coke bed and coke-free layer. The predicted results show a well-organized flow pattern: two large-scale recirculation zones are separated vertically at the taphole level. This flow pattern controls the temperature distribution in the liquid phase, so that the temperature remains nearly uniform in the upper zone, but changes mainly across the lower zone. The effects of several factors were examined, such as cases comparing fluid buoyancy with constant fluid density as well as the shape and position of the coke free zone (i.e. based on reported dissection studies). Natural convection is found to be most important for the liquid metal flow patterns observed. Comparison with the plant data shows that the refractory pad temperature is under-predicted when assuming intact hearth lining. The pad temperature is very sensitive to the erosion of protection layer in the hearth lining.
\end{abstract}

KEY WORDS: blast furnace hearth; metal flow; heat transfer; modelling.

\section{Introduction}

The campaign life of an ironmaking blast furnace $(\mathrm{BF})$ is mainly determined by the wear of hearth refractory. It is therefore important to improve the understanding of hot metal flow and heat transfer in the hearth, since this strongly affects the erosion of a BF hearth. However, the hostile internal conditions in the hearth means that no direct measurements of the in-furnace conditions and remaining hearth lining thickness are possible, and use of indirect measurements such as thermocouple readings is necessary. In this sense, computational fluid dynamics (CFD) models are powerful exploratory tools, particularly in situations where plant trials are expensive and complicated.

Molten iron (or hot metal) and slag collect at the bottom of the BF, filling the coke bed/deadman of the hearth. The lighter slag remains on the top of liquid iron layer and the liquids are drained out periodically through a taphole. Since three-dimensional modelling of the transient multiphase flow coupled with liquid-refractory heat transfer is still challenging at present time, the actual in-furnace conditions can be simplified in many experimental studies and modelling works, depending on the specific interest and task. ${ }^{1,2)}$

The studies of hot metal flow are largely relevant to refractory erosion, heat transfer and solidification.,4) Early CFD models assumed a single phase flow and used crude computational grids (less than 1000 nodes). Yoshikawa and Szekely ${ }^{5}$ investigated the recirculatory flow induced by natural convection and its effect on dissolution of carbonaceous refractory into the melt, based on an unrealistic coke free assumption. They investigated only the temperature induced flow in a porous-free hearth. Shibata et $a l .{ }^{6)}$ used a three-dimensional model to examine the effects of different coke zones or deadman positions, namely, fully packed hearth, sitting deadman with coke-free gutter, floating deadman with coke free gutter, and floating deadman with flat bottom. They also investigated the radial distribution of porosity and different taphole lengths and positions. An empirical heat transfer coefficient between molten iron and refractories was used. While this approach could account for the effect of turbulence on the heat transfer at the wall boundaries, the heat transport through the bulk flow was still calculated based on laminar flows.

Some models with refined grids did not explicitly include refractory walls. Preuer et al..$^{7)}$ predicted three-dimensional flows and temperature profiles with special reference to the influences of permeability, shape and movement of the deadman, porous free regions, temperature and tapping during a tapping cycle. However, no turbulence and particleinduced thermal dispersion were considered. Kurita and Ogawa $^{8)}$ simulated cases with a floating deadman, a spatial variation in deadman porosity, a deadman with an imper- 
meable central region, and a non-uniform inlet temperature (decreasing from the raceway to the centre). Kowalski et $a l .{ }^{9)}$ described a model that included calculations for the dissolution rate of carbon from refractories for a sitting and a floating deadman. In a normal tapping process, the coke bed may float in hot metal (viz. floating deadman), rest on the refractory pad near the middle of hearth (viz. sitting deadman with coke free gutter) or fill the hearth completely (viz. sitting deadman). ${ }^{10)}$ Another numerical model calculated the thermal conduction across the solid hearth refractory without considering the effect of the fluid flow and coke bed. For example, the heat transfer model for the hearth lining ${ }^{11,12)}$ assumed a fully mixed liquid and no thermal gradients present in the molten metal pool. Takatani et $a l .{ }^{3)}$ developed a CFD model with heat transfer to estimate the transient erosion of the blast furnace hearth. The effects of dripping iron distribution, the coke free layer size, production rate, thermal conductivity of carbon brick and resistance of coke bed were examined. Research was also carried out based on the experimental and modelling analysis of the drainage process, particularly in terms of the temporal evolution of the inter-phase surface. ${ }^{13-15)}$ These studies focused on the slag flow or slag-metal two-phase flow, but in absence of heat transfer.

While the above models ignore the effect of turbulence, Panjkovic et al. ${ }^{16)}$ explicitly included an algebraic turbulence model in their model and predicted the fluid flow pattern and temperature profiles in the hot metal and the hearth refractories for a real blast furnace. However, since the simple algebraic model applies only to flows through porous media, separate treatments were required for the coke bed and coke free zones. Specifically, in calculating the turbulence eddy viscosity in the coke free zone, the turbulence length scale was assumed as fixed and was evaluated as the height of coke free layer.

In spite of the many investigations described above, a general description of the liquid iron flow distribution inside a blast furnace hearth is difficult to obtain, due to the complexity of the real system and simplifications and assumption made in the numerical models. The current study aims to develop a new three-dimensional numerical model to resolve the complex flow structures within the ironmaking hearth. Based on the work of Panjkovic et al., ${ }^{16)}$ the current model uses a refined computational grid and applies a new set of mathematical equations for turbulent flow/heat transfer in porous media. Moreover, the flow pattern and heat transfer are described and analysed in more details to extend the knowledge on the liquid metal flow. The modelling is limited to single-phase iron flow, principally because the interest here is in understanding the impact of flow on hearth refractory erosion.

\section{Model Governing Equation}

The macroscopic governing equations for flow in porous media are often derived using volume-averaging of the microscopic equations. The mean flow equations for continuity and momentum balance in an isotropic porous medium can be written in coordinate free tensor notation as,

$$
\nabla \cdot(\gamma \rho \mathbf{u})=0
$$

$$
\begin{aligned}
& \nabla \cdot(\gamma \rho \mathbf{u u})-\nabla \cdot\left(\mu_{\text {eff }} \gamma\left(\nabla \mathbf{u}+(\nabla \mathbf{u})^{\mathrm{T}}\right)\right) \\
& =-\gamma \nabla\left(p+\frac{2}{3} \rho k\right)+g \rho \beta\left(T-T_{\text {ref }}\right)-\gamma \mathbf{R}
\end{aligned}
$$

where

$$
\begin{aligned}
& \mu_{\mathrm{eff}}=\mu+\mu_{\mathrm{t}} \\
& \mu_{\mathrm{t}}=\rho c_{\mu} \frac{k^{2}}{\varepsilon}
\end{aligned}
$$

They are a generalisation of Darcy's Law commonly used for flows in porous media and of the Reynolds-averaged Navier Stokes equations, with an eddy viscosity accounting for the turbulent effect. The second term in the right hand side of Eq. (2) is the fluid buoyancy force due to thermal expansion. The last term in Eq. (2) represents a resistance to flow in porous media. Based on the well-known Ergun's equation, the resistance force for flow through a bed of particles is given by,

$$
\mathbf{R}=150 \mu \frac{(1-\gamma)^{2}}{\gamma^{2} \phi^{2} d_{\mathrm{p}}^{2}} \mathbf{u}+1.75 \rho \frac{1-\gamma}{\gamma \phi d_{\mathrm{p}}}|\mathbf{u}| \mathbf{u}
$$

The turbulent viscosity is determined by applying the $k-\varepsilon$ model modified by Nakayama and Kuwahara, ${ }^{17)}$ in which an extra source term due to solid particles is added in the turbulence model equations (namely, kinetic energy and its dissipation) for normal fluid flow. This model allows unified treatments for the liquid iron flow over the entire hearth. The comparison of this model with other models was discussed by Guo et al. ${ }^{18)}$

Assuming thermal equilibrium between the fluid and solid matrix, namely $T_{\mathrm{f}}=T_{\mathrm{s}}=T$, where the subscripts, $\mathrm{f}$ and $\mathrm{s}$, refer to fluid and solid, respectively. For saturated rigid porous media, the energy equations for the fluid and solid phases can be written as,

$$
\begin{array}{r}
\left(\rho c_{\mathrm{p}}\right) \nabla \cdot(\mathbf{u} T)-\nabla \cdot\left(\left(\lambda_{\mathrm{f}}+\frac{c_{\mathrm{p}} \mu_{\mathrm{t}}}{\sigma_{\mathrm{T}}}\right) \nabla T\right)=0 \\
\nabla \cdot\left(\lambda_{\mathrm{s}} \nabla T\right)=0
\end{array}
$$

Spatial integration of the two microscopic energy equations yields the macroscopic energy equation,

$$
\gamma \rho c_{\mathrm{p}} \nabla \cdot(\mathbf{u} T)=\nabla \cdot\left\{\boldsymbol{\lambda}_{\mathrm{P}} \cdot \nabla T\right\}
$$

where $\lambda_{\mathrm{P}}$ is a modified thermal conductivity, which is a second rank tensor and can be expressed as,

$$
\boldsymbol{\lambda}_{\mathrm{P}}=\left(\lambda_{\mathrm{stg}}+\gamma \frac{c_{\mathrm{p}} \mu_{\mathrm{t}}}{\sigma_{\mathrm{T}}}\right) \boldsymbol{\delta}+\boldsymbol{\lambda}_{\mathrm{tor}}+\boldsymbol{\lambda}_{\mathrm{dis}}
$$

where $\lambda_{\text {stg }}$ is the effective stagnant thermal conductivity of the saturated porous medium, defined as,

$$
\lambda_{\mathrm{stg}} \equiv \gamma \lambda_{\mathrm{f}}+(1-\gamma) \lambda_{\mathrm{s}}
$$


The apparent conductivity tensors, $\boldsymbol{\lambda}_{\text {tor }}$ and $\boldsymbol{\lambda}_{\text {dis }}$, are introduced to describe the tortuous molecular diffusion and the thermal dispersion, respectively.

$$
\gamma \rho c_{\mathrm{p}} \nabla \cdot(\mathbf{u} T)=\nabla \cdot\left\{\left[\left(\lambda_{\mathrm{stg}}+\frac{\gamma c_{\mathrm{p}} \mu_{\mathrm{t}}}{\sigma_{\mathrm{T}}}\right) \delta+\lambda_{\text {tor }}+\lambda_{\mathrm{dis}}\right] \cdot \nabla T\right\}
$$

This equation is similar in format to the generic advectiondiffusion equation that governs the energy transport in the fluid flow through porous media except for a modified thermal conductivity.

The extra terms in the effective conductivity are usually prescribed in normalised forms. $\lambda_{\text {tor }} / \lambda_{f}$ depends on the Peclet number, Pe, and the ratio of thermal conductivity between the solid structure and the fluid, $\lambda_{\mathrm{s}} / \lambda_{\mathrm{f}}$. Some data for $\lambda_{\text {tor }} / \lambda_{\mathrm{f}}$ are available only for $\lambda_{\mathrm{s}} / \lambda_{\mathrm{f}}=2-100$. For the current liquid iron-coke system, $\lambda_{\mathrm{s}} / \lambda_{\mathrm{f}}=0.12$. According to Nakayama and Kuwahara, ${ }^{19)} \lambda_{\text {tor }} / \lambda_{\mathrm{f}}$ decreases as Pe increases. It also decreases as $\lambda_{\mathrm{s}} / \lambda_{\mathrm{f}}$ decreases. With increasing Pe, the contribution due to thermal dispersion dominates that due to tortuosity. Therefore the tortuosity term can be neglected.

The thermal dispersion is non-isotropic, with a higher level in the flow (longitudinal) direction than in the transverse direction. Empirical correlations were given by Kuwahara and Nakayama ${ }^{20)}$ in terms of the Peclet number and porosity. For longitudinal dispersion at low and high Peclet number ranges:

$$
\begin{gathered}
\frac{\left(\lambda_{\text {dis }}\right)_{X X}}{\lambda_{\mathrm{f}}}=0.022 \frac{\mathrm{Pe}_{\mathrm{p}}^{2}}{1-\gamma} \text { for } \mathrm{Pe}_{\mathrm{p}}<10 \\
\frac{\left(\lambda_{\mathrm{dis}}\right)_{X X}}{\lambda_{\mathrm{f}}}=2.7 \frac{\mathrm{Pe}_{\mathrm{p}}}{\gamma^{1 / 2}} \text { for } \mathrm{Pe}_{\mathrm{p}} \geq 10
\end{gathered}
$$

For transverse dispersion:

$$
\begin{aligned}
& \frac{\left(\lambda_{\text {dis }}\right)_{Y Y}}{\lambda_{\mathrm{f}}}=0.022 \frac{\mathrm{Pe}_{\mathrm{p}}^{1.7}}{(1-\gamma)^{1 / 4}} \text { for } \mathrm{Pe}_{\mathrm{p}}<10 \ldots . \\
& \frac{\left(\lambda_{\text {dis }}\right)_{Y Y}}{\lambda_{\mathrm{f}}}=0.052(1-\gamma)^{1 / 2} \mathrm{Pe}_{\mathrm{p}} \quad \text { for } \mathrm{Pe}_{\mathrm{p}} \geq 10 \ldots
\end{aligned}
$$

where $\mathrm{Pe}_{\mathrm{p}}$ is a modified Peclet number, given by

$$
\mathrm{Pe}_{\mathrm{p}}=\operatorname{Pe}(1-\gamma)^{1 / 2}
$$

For a given mass flow rate and particle size, an increase in porosity $\gamma$ enhances turbulent mixing and simultaneously, dampens the thermal dispersion within the porous media. In the computation, the longitudinal direction aligns with the local velocity vector, which changes with location.

\section{Numerical Model and Boundary Conditions}

A typical blast furnace geometry is considered in this study, e.g. BlueScope Steel's Port Kembla No. 5 Blast Fur- nace. For convenience, many of the dimensions can be denoted by the location of the refractory corners in terms of their axial and radial coordinates (Fig. 1). The taphole is $60 \mathrm{~mm}$ diameter with a $12.5^{\circ}$ angle. The hearth is treated as symmetric about the plane defined by the hearth centreline and the taphole, so only one half of the cylinder needs to be modelled. For computational convenience, the top inlet or iron-slag interface, is chosen to be at some distance above the taphole. Other investigators have used this treatment. $3,6,7,16)$

The numerical computations were performed with the general purpose fluid flow package ANSYS-CFX, a finite volume based CFD software which provides a solver for a standard set of Navier-Stokes equations for fluid flow and various user subroutines. A three-dimensional, block-structured numerical grid is shown in Fig. 2. The grid is arranged in such a way that the resolution is high in regions where velocities or temperature tends to vary greatly, e.g., near taphole, in the vicinity of the ceramic steps and in the radial direction. The total number of grid points is about 400000 . The hearth condition is assumed to be at steady state, with only liquid iron being considered. The taphole is represented as a hollow enclosure, without coke inside it. Coke and iron temperatures are assumed equal.

For boundary conditions at the inlet surface, a constant temperature of $1550^{\circ} \mathrm{C}$ is specified. The inlet velocity is set

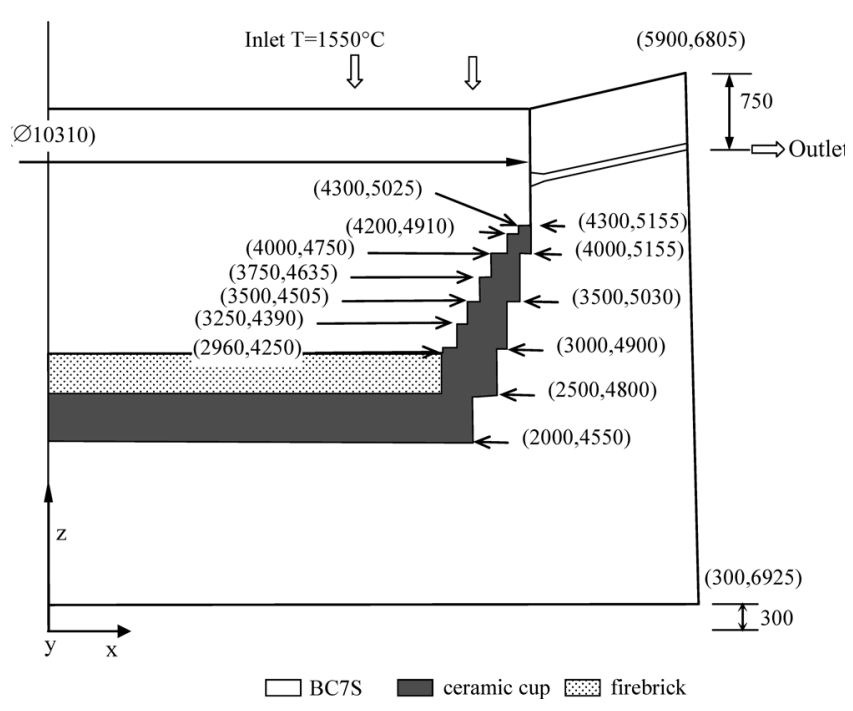

Fig. 1. Geometric dimensions of the hearth considered.

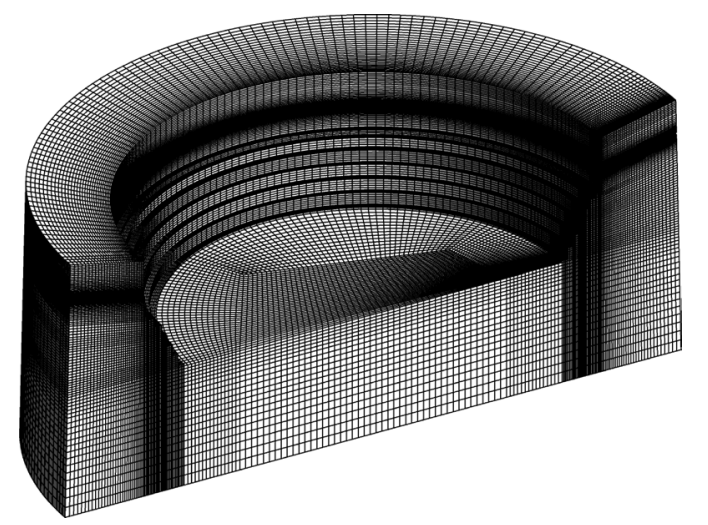

Fig. 2. Computational grid of the hearth geometry (only the hearth refractory section is shown). 
to zero over the central region of the hearth, whilst over the peripheral ring, it is assumed to be uniform. ${ }^{7)}$ The inlet velocity over the peripheral ring is based on a mass flowrate of $40 \mathrm{~kg} / \mathrm{s}$, corresponding to one half of the hot metal productivity from the blast furnace considered. At the wall, a no-slip condition exists on the hot face of the refractory walls. The standard log law wall function is applied for the velocity. The thermal boundary layer is modeled using the thermal law-of-the-wall function of Jayatilleke. ${ }^{21)}$ Temperatures at the cold face of the refractory are explicitly specified. A temperature profile is assumed for the cold face of the sidewall, so that the simulated temperatures match the measured values by the thermocouples located $165 \mathrm{~mm}$ inside the outer refractory wall. For the bottom wall, the temperature varies with radius, so as to match measured pad temperature at $z=0.3 \mathrm{~m}$. The upper surface of the refractory wall is adiabatic. The typical values used for the physical properties are listed in the nomenclature. For the refractory, the thermal conductivity of each material is fitted as a linear function of temperature based on the data of Panjkovic et al. ${ }^{16)}$

\section{Results and Discussion}

It is well recognized that various coke bed/deadman shapes and positions are possible in the blast furnace hearth. In this study, six different cases are considered, from simple to complex configurations. The following configurations are shown schematically in Fig. 3:

(a) Fully sitting bed

(b) Uniform coke free layer

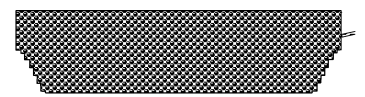

(a)

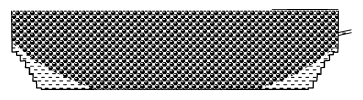

(c)

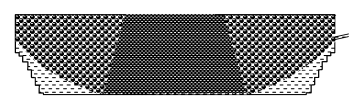

(e)



(b)

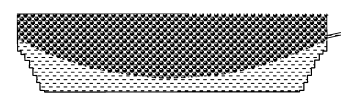

(d)

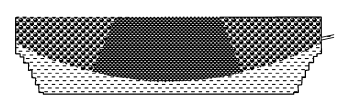

(f)
Fig. 3. Schematic of the coke bed condition for cases (a)-(f). coke bed; 疅, coke free region; (c) Sitting bed with coke free gutter

(d) Non-uniform coke free layer

(e) Sitting bed with coke free gutter and with fines

(f) Non-uniform coke free layer with fines.

The highest point of the coke free layer is always kept below the taphole entry. For cases e and $\mathrm{f}$, the particle size and porosity in the fine coke region are assumed to be $5 \mathrm{~mm}$ and 0.2 , respectively, while they are $30 \mathrm{~mm}$ and 0.35 , respectively, for the remaining regions.

\subsection{General Features}

The predicted results show a common flow pattern: two distinct flow zones are identified, which can be separated by a nearly horizontal boundary somewhere below the taphole level. While the iron melt is nearly stagnant in the lower zone (except in the coke free layer), the velocity in the upper zone is relatively high. Post et al. ${ }^{22)}$ also observed a similar phenomenon in a 2-D model, a clear stratification between a high-speed zone and a low-speed zone. The iron moves almost horizontally except near the refractory wall, where it tends to move downward because the fluid in contact with the wall is slightly cooler and denser than that away from the wall (Fig. 4). Note that the flow in this thin layer of iron is difficult to resolve computationally by an otherwise coarse finite mesh-however, this is necessary because of the relatively high velocity in this region which, for example, may result in a higher erosion rate of the refractory. Figure 5 shows the flow vectors at a horizontal plane at the taphole level-despite the different coke bed structures, the iron moves towards the taphole or around the low permeability zone. For the majority of the hearth crosssection, the liquid entering the top inlet moves directly towards the taphole (Fig. 6), while over a small section of the inlet closest to the side wall at the opposite side of the taphole, the fluid moves initially away from and then turns back towards the taphole. In fact, a 3D visualization indicates that the direction of flow at the inlet (or surface) is towards the refractory wall in the radial direction (Fig. 7), induced by the downward flow at the wall surface.

Generally, the flow behaviour near the hearth side wall is complex due to the complex geometry of the refractory and the large temperature gradient. Small recirculation loops with the length scale of refractory (ceramic) steps exist. This is particularly true for the case of the unhindered coke free zone.

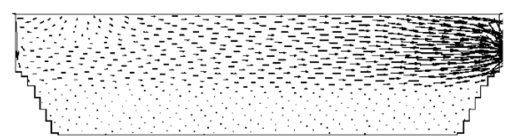

(a)

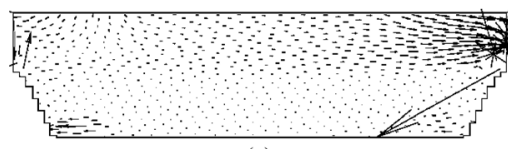

(c)

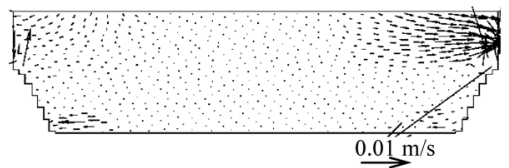

(e)

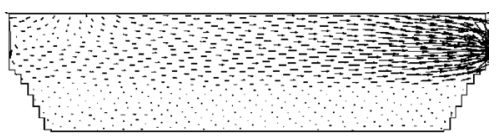

(b)
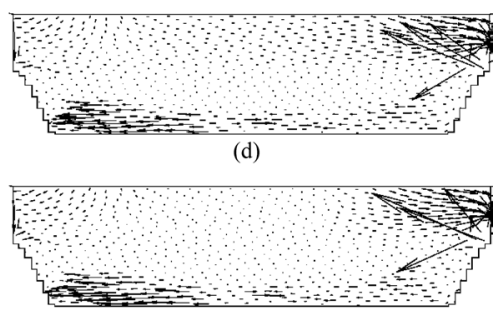

(f)

Fig. 4. Velocity vectors in the symmetry plane for cases (a)-(f). 


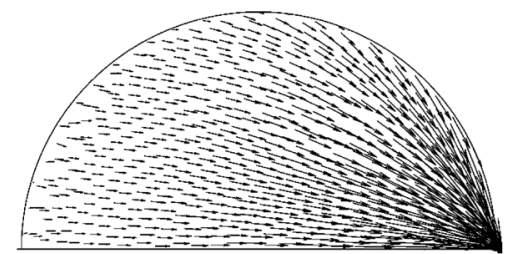

(a)

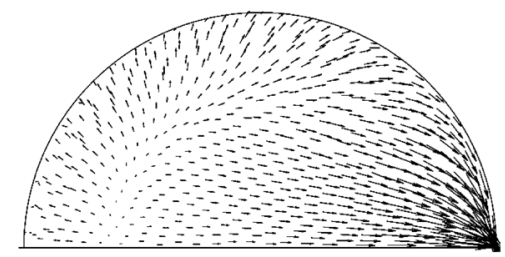

(c)

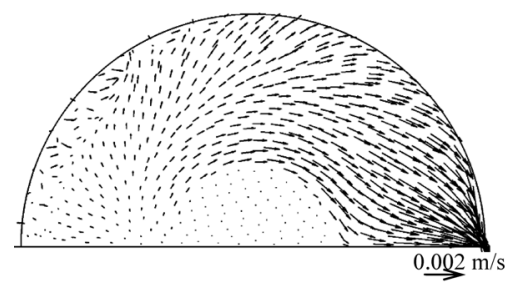

(e)

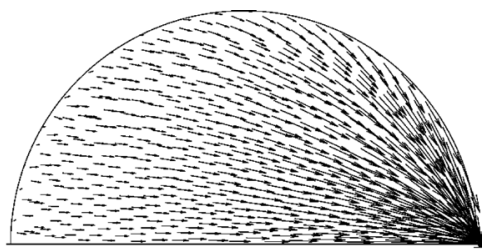

(b)

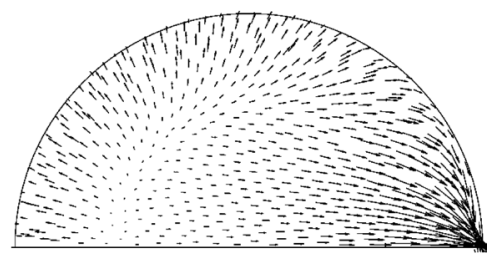

(d)

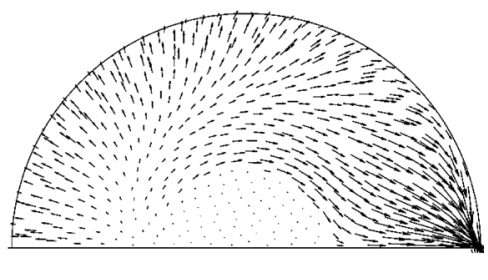

(f)

Fig. 5. Velocity vectors in a horizontal plane at taphole entry level for cases (a)-(f).

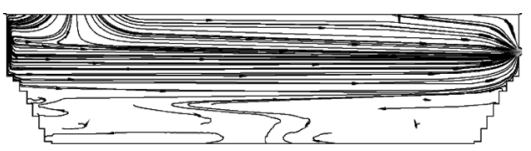

(a)

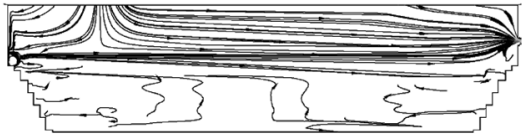

(c)

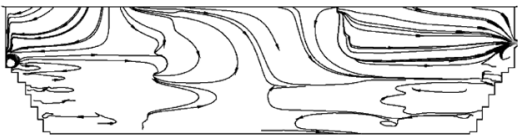

(e)

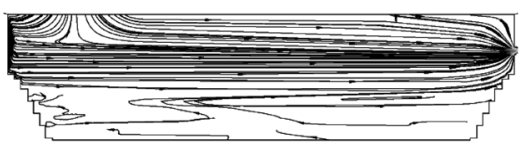

(b)

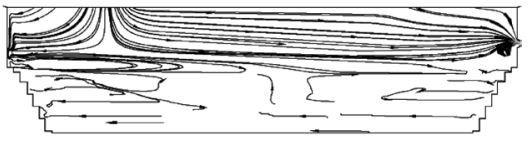

(d)

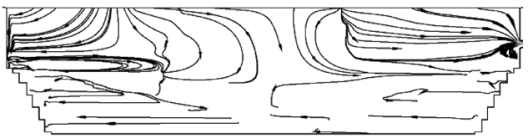

(f)

Fig. 6. Comparison of streamlines for cases (a)-(f).

This flow pattern determines the temperature distribution in the liquid phase, so that the temperature remains nearly uniform in the upper zone, as shown in Fig. 8. The high heat transfer efficiency is caused by the bulk flow advection, turbulent diffusion and thermal dispersion, which strongly depend upon the fluid velocity. Temperature gradients occurs mainly in the lower zone due to the low velocity. For this reason, the temperature profile within the hearth pool appears to be smooth or uniform across the diameter, while the vertical profile is relatively sharp. In other words, the isotherms are nearly horizontal within the liquid pool, a phenomenon, referred to as "horizontal thermal layering of the fluid". ${ }^{23)}$ The bottom part of coke bed just above the coke free layer remains stagnant in all six cases considered, not only in the case of fines (i.e., cases e and f). The extremely low velocity together with low temperature makes it possible for solidification of metal to occur in the hearth bottom, as found by Watakabe et al. ${ }^{24)}$ Within the solid refractory, several isotherms are concentrated towards the upper portion of the bottom refractory. This is attributed to the low conductivity of the protective layer material (firebrick and ceramic layer) used in the region.

For the base case (Case a in Fig. 3), since the incoming fluid moves basically in the horizontal direction, heat transfer in the vertical direction from top to bottom is dominated by turbulence and by the thermal dispersion caused by the microscopic process at the coke particle scale and, in the extreme case of zero velocity, by the molecular conduction only, whereas the heat transfer between the two regions through the advection contributed by the bulk flow is of secondary importance. Due to the overall low velocity in the lower zone, the slow mixing causes temperature gradient to occur mostly in this region. This flow pattern is sustainable in the hearth, since the liquid in the lower stagnant zone contacts the cooler bottom refractory and becomes heavier, which makes it in a relatively stable state. Therefore, the flow-heat transfer coupling and natural convection are critical to the current flow pattern.

The current flow behaviours, featured by the high velocity in the upper zone and the significant variation of tem- 




Fig. 7. 3D streamlines starting from the inlet for case (d).

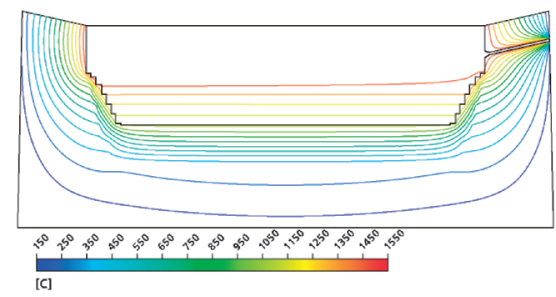

(a)

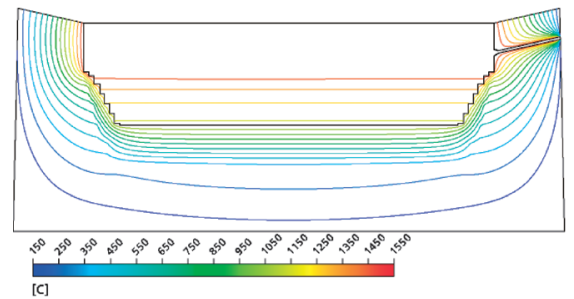

(c)

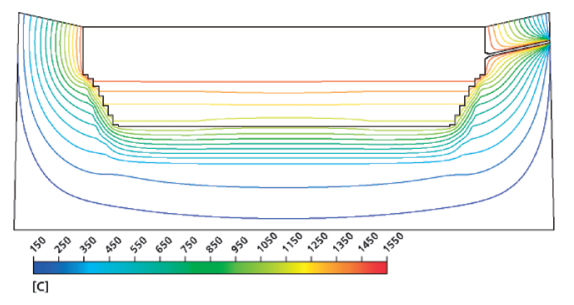

(e) perature in the lower zone, appear to be more complicated than that calculated by Shibata et al. ${ }^{6}$ Apart from different modeling conditions (e.g., uniform thermal conductivity of higher value for the refractory), Shibata et al. used a much coarser mesh and did not consider the turbulent effect and thermal dispersion in the fluid phase, thus the accuracy of their results may not be satisfactory. The current flow pattern appears to be more regular than that predicted by Panjkovic et al., ${ }^{16)}$ where a range of chaotic recirculating eddies are induced by natural convection. The isotherms and temperature profile also become smoother. The model performance has been demonstrated by its capability to capture not only more flow structures, but also a general flow pattern. These improvements represent better converged behaviors

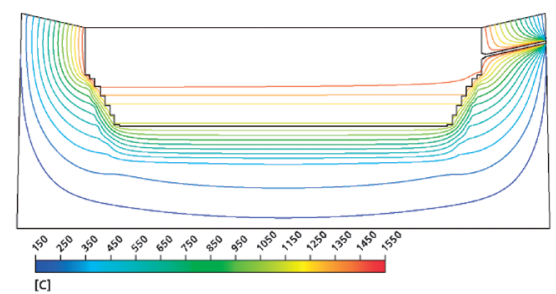

(b)

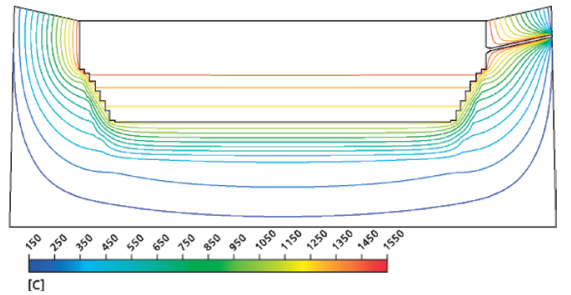

(d)

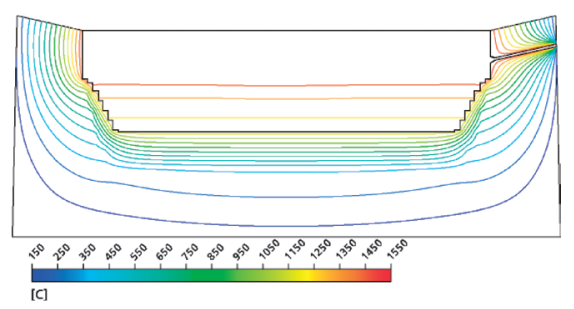

(f)

Fig. 8. Comparison of temperature contours for different CFZ shapes for cases (a)-(f).
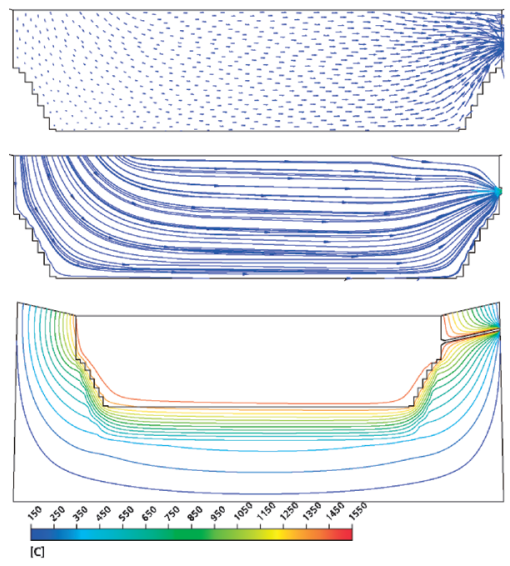

(a)
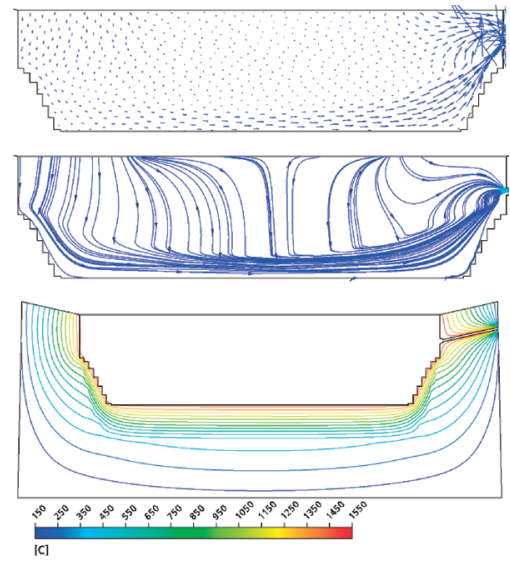

(b)

Fig. 11. Liquid flow (shown as vectors, streamlines) and temperature contours for the case of no buoyancy. (a) Fully sitting bed; (b) non-uniform coke free layer. 
and thus more reliable results. The under-predicted pad temperature is regarded as the consequence of other physical phenomena rather than the model formulation.

In order to better understand the hearth phenomenon within the hearth, we have examined the effects of several factors such as two- versus three-dimensional regimes, fluid buoyancy versus constant density, different shapes and positions of coke free layer. Some of these will be discussed below.

\subsection{Effect of the Shape and Position of Coke Free Layer}

The importance of the coke free zone has been recognized previously. ${ }^{6,14)}$ From the present results, velocity in the coke free zone (CFZ) is generally stronger and more chaotic than in the coke bed zone, although the CFZ is located in the lower part of the hearth. For the conditions chosen, the difference in the coke bed structure hardly affects the global flow pattern, i.e., two distinct zones still exist, despite different local velocity field within each CFZ. Due to low permeability, the velocity in the fine coke region is extremely low (cases e and f). Interestingly, liquid is forced to move horizontally (rather than vertically) in the annular region around the fines (cases e and f), suggesting that the flow pattern is quite stable.

Figure 8 shows the temperature contours for the six cases considered. The temperature gradient in the hearth pool is lower than that in the refractory. The overall temperature distribution is uniform in the horizontal direction in the hearth pool - only cases a and b show that some contour lines follow the streamlines near the taphole. The isotherms may be distorted by the fine coke region (cases e and f) and such behaviour may become more obvious when the fine coke zone sits on the bottom refractory (case e), where slight spreading of the isotherms in the firebrick and ceramic layer of the refractory can be seen.

Many BFs are now equipped with a comprehensive array of thermocouples in the hearth refractory. For the purpose of model validation, measured temperatures are presented together with simulation results. The comparison of the model results and recorded temperatures, indicated as discrete points (mean value) and error bars (the range of fluctuation), is shown in Fig. 9 in the form of radial profiles of temperature at three levels $(z=0.3 \mathrm{~m}, 0.9 \mathrm{~m}$ and $1.5 \mathrm{~m})$. The thermocouple temperature distribution is reasonably well predicted, although there are differences in the absolute values. The predicted temperature profile at level $z=1.5 \mathrm{~m}$ appears less smooth, which reflects the effect of the complex steps at the corner for the hearth lining. Among the six cases considered, temperature in the bottom lining is lowest for case a without coke-free layer, and highest for case d, which has a relatively large extent of coke-free zone both horizontally and vertically. The effective volume for the fluid is also reduced by the presence of a fine coke region, thus the fluid velocity tends to increase and subsequently heat transfer will be enhanced. In case e, the temperature at the centre at $z=1.5 \mathrm{~m}$ shows a flatter profile commensurate with the contact between the less permeable bed and the refractory. It is noted that the peak temperature at $z=1.5 \mathrm{~m}$ differs by a maximum of $30^{\circ} \mathrm{C}$ for all the cases considered, suggesting that the pad temperatures are more sensitive to

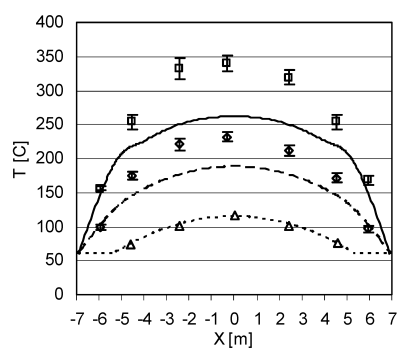

(a)

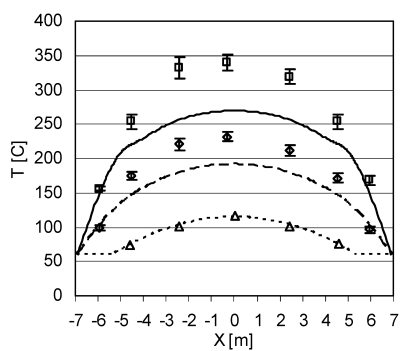

(c)

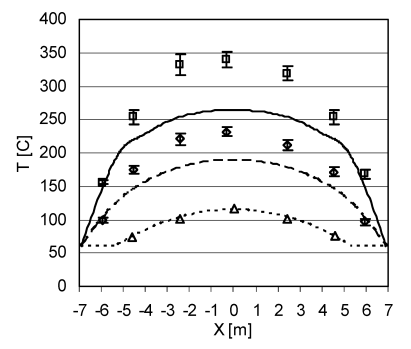

(e)

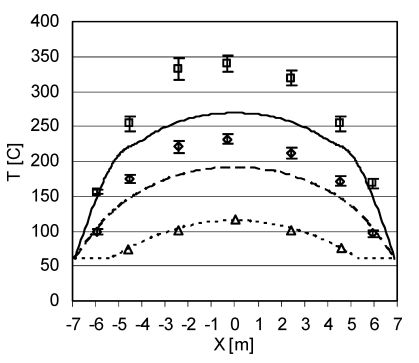

(b)

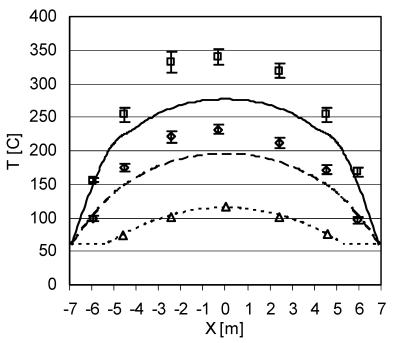

(d)

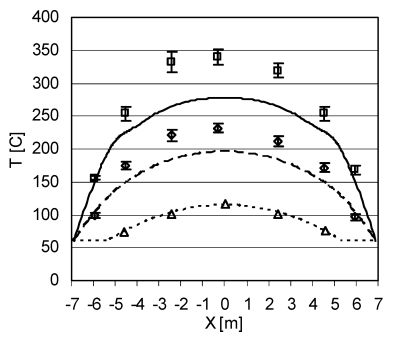

(f)
Fig. 9. Comparison of radial profiles of temperature between simulation and measurements for cases (a)-(f): $\square, \bigcirc, \triangle$, measured at the levels of $1.5,0.9$ and $0.3 \mathrm{~m}$ respectively; ,,$---- \cdots \cdots$, simulated at the corresponding levels.

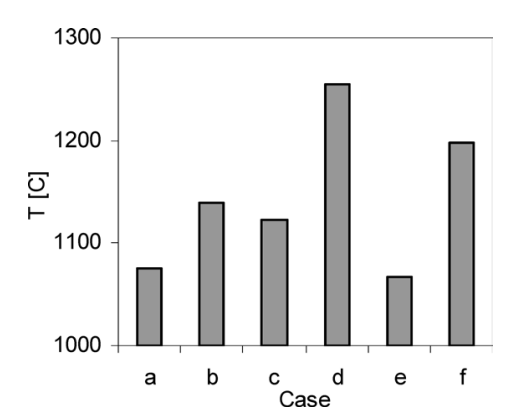

Fig. 10. Interfacial temperature at the centreline for cases (a)-(f).

the thermal conductivity of the ceramic layer than to the coke bed structures. The pad temperature alone may be insufficient to effectively monitor the change in flow structure inside the hearth when the protecting layers are intact. However, the interfacial temperature on the pool bottom did vary by up to $170-200^{\circ} \mathrm{C}$, as shown in Fig. $\mathbf{1 0}$.

In order to understand the under-predicted pad temperature, the effects of inlet temperature, thermal dispersion and liquid metal level were considered. It was found that these parameters affect the central temperature profile, but not the overall flow patterns and temperature distributions. A rise in the inlet temperature by $100^{\circ} \mathrm{C}$ has little effect on the bottom interface temperature and hence the pad temperature. Regarding the liquid iron level, taking case a as an example, a lowered inlet location from 1.1 to $0.47 \mathrm{~m}$ above the 
taphole does not increase the pad temperature.

\subsection{Effect of Buoyancy}

The velocity field is determined by a combination of forced convection and natural convection. The former results from the balance of inlet-to-outlet pressure difference and coke bed resistance, whereas the latter is driven by the buoyancy force, which is induced by a varying density due to the thermal expansion of the fluid under gravity. The inclusion of the buoyancy provides a real coupling between the flow and heat transfer. The existence of a stagnant zone predicted on the bottom results from a dominating buoyancy force. Disregarding this force, the flow patterns (Fig. 11) appear to be much more sensitive to any change of the coke free zone volume and is fundamentally different from the normal cases considered above (where buoyancy is included). For the case of a sitting bed, the bulk flow is quite regular, from the far side of the hearth to the taphole, without forming any recirculation eddies. There is little stratification in fluid temperature and the heat transfer in this case is dominated by the forced advection of the bulk flow. This flow pattern appears to be similar to that calculated by Shibata et al. ${ }^{6}$ ) and Takatani et al. ${ }^{3)}$ (assuming a constant density in these studies) but such a flow pattern should be verified in a natural convection dominated system. It is expected that natural convection will be less important as the coke bed resistance increases. In a hot water model experiment, Shinotake et ll. $^{2)}$ observed a stagnant zone and transition to regular streamlines when the liquid rate increases and particle size decreases.

The temperature is basically uniform over a large portion of the melt pool, while the change in temperature is mostly restricted to the near-wall regions or those corner regions of the refractory-hot metal interface. It is obvious that the flow behavior depends strongly on the shape and level of coke free zone. For example, for the case of floating coke bed, the coke free layer acts as a short circuit for the liquid flow, directing the hot liquid from the inlet vertically to the hearth bottom. This further reduces the temperature difference in the hearth pool and subsequently increases the pad temperature compared with the case of a fully packed bed. Ignoring the buoyancy also reduces the vertical temperature difference in the sidewall thermocouple locations and deviates from the measured values; hence, this type of flow pattern is unlikely to occur. Such a significant difference suggests that any knowledge obtained from cold model experiments (without fluid density change) or from isothermal numerical simulations should be treated with care.

The temperature profile along the centreline is shown in Fig. 12. The buoyancy effect is obvious only in the liquid part above $z=3.0 \mathrm{~m}$. In the case where no buoyancy is considered, temperature changes significantly in the boundary layer, whereas it is not the case when the buoyancy is included. In the solid refractory region, the temperature gradient is inversely proportional to the thermal conductivity of the materials. For example, the temperature changes most sharply across the firebrick and ceramic cup in the range $z=2.0-3.0 \mathrm{~m}$. Overall, the thermal conduction across the solid refractory dominates the entire heat transfer from hot metal to the surrounding. Due to high thermal resistance, the ceramic cup and firebrick may, to some degree,

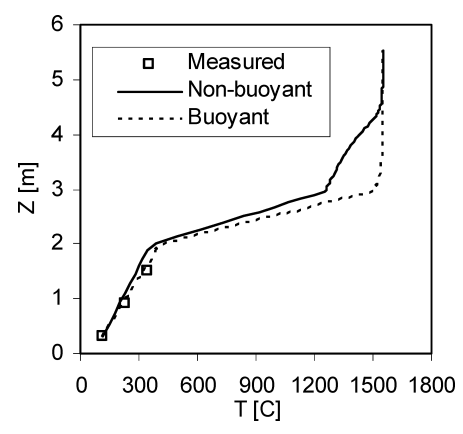

Fig. 12. Temperature profile along the centreline showing the effect of buoyancy.

dampen some of the changes in hearth conditions, i.e., the pad temperature becomes less sensitive to a change in the shape of coke free zone or inlet temperature.

It is noted that the buoyancy force is negligible for the case of a liquid with a low thermal expansion coefficient, such as slag. In this case, the turbulence/dispersion makes little difference to the calculated result. However, the contribution of turbulence/dispersion has been found to be much stronger when a stagnant zone due to natural convection exists. As discussed in Sec. 2, the presence of coke particles would generate additional turbulence and thermal dispersion compared with the coke-free region. These phenomena are rarely considered in previous work carried out in BF hearth research. The calculation shows that the thermal dispersion is the same or of a higher magnitude than the thermal conductivity of the liquid materials in many regions. The turbulent viscosity is even much higher than the laminar viscosity of hot metal. Therefore, these terms create effective transport properties that are at least as important as the material properties of liquid metal. Their omission, though making little difference to the overall flow pattern, could reduce the bottom hot face temperature by up to $100^{\circ} \mathrm{C}$, subsequently reducing pad temperatures by about $17^{\circ} \mathrm{C}$. The turbulent effect on the flow distribution is particularly important in the taphole region and the coke free region. As a result, the wall shear stress is much smaller at the taphole region, while it is higher in the coke free zone, compared with a laminar flow.

\subsection{Effect of Liquid Properties}

The hearth is known to contain liquid iron and slag. In this study, we consider one of them only. All the results reported above are obtained for liquid iron which is more related to the heat transfer and erosion in the hearth. However, the liquid properties may vary with temperature and composition. As an extreme limit in the numerical experiment, the hot metal is replaced by pure slag with the properties given by Saito et al. ${ }^{25)}$ and Inaba et $a .^{26)}$ The predicted slag flow patterns (Fig. 13) are found to be much similar to the metal flow for the case of no buoyancy, but significantly different from the typical hot metal flow as discussed above. The effect of coke bed structure is clearly visible, whereas the natural convection is negligible. This is expected when considering the significant difference in fluid properties such as viscosity, thermal conductivity and coefficient of thermal expansion. For example, slag is much more viscous than hot metal by two orders of magnitude, so 


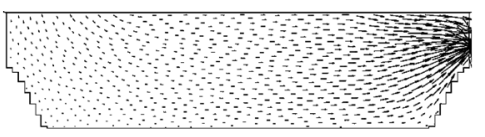

(a)

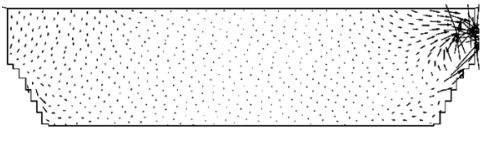

(c)

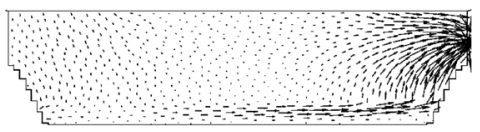

(b)

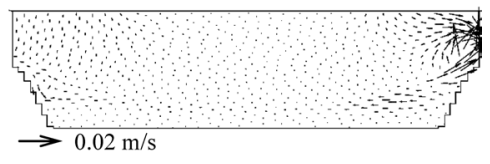

(d)

Fig. 13. Velocity vectors in the symmetry plane for slag only flow for cases (a)-(d).

the coke bed resistance dominantly controls the overall flow pattern. The temperature is nearly uniform over most part of the hearth volume, so the contribution of turbulence/dispersion is unimportant relative to that for the hot metal flow. The predicted pad temperatures are still lower than the measured ones. However, we can clearly see significant differences between slag flow and metal flow, and stronger sensitivity of slag flow to the shape of coke-free zone and coke bed structure compared with the hot metal flow. Therefore, the predicted phenomena described in previous sections represent only the liquid iron flow behaviours in the lower part of the hearth, but do not represent slag flow, nor the liquid phase as a whole. Aware of the strong effect of liquid properties, the substitute liquid (if not the exact process liquids) in a physical model study should be selected properly in order to reproduce correctly the flow behaviour in reality, whether liquid iron or slag flow is concerned.

\subsection{Effect of the Hearth Lining Thickness}

Port Kembla No. 5 Blast Furnace was installed with an array of thermocouples in the hearth refractory. From a time series plot of centre pad temperatures (Panjkovic et $a l{ }^{16)}$ ), a sharp rise of approximately $100^{\circ} \mathrm{C}$ was noted in 1995. It was believed that: (a) the hearth refractory surface was intact before the sudden change in pad temperature; (b) this event was caused by the loss of firebrick layer. Based on the current model simulation results, such a temperature increase was not possible with the assumed inlet iron temperature and intact refractory lining before 1995. It is found that to match the pad temperature, the temperature at the liquid-refractory interface must be $1550^{\circ} \mathrm{C}$ at minimum. This would require an elevated hot metal surface temperature as high as $1700^{\circ} \mathrm{C}$. Also, as shown above, the pad temperature distribution is relatively insensitive to the inside conditions early in the campaign, being controlled by the heat transfer across the hearth refractory, particularly the low thermal conductivity of the ceramic cup and firebrick. Hence, based on the current numerical model results described previously, the most likely explanations are that some erosion or iron penetration of the firebrick layer has occurred.

A special case where $30 \%$ of the firebrick layer is partly lost was examined. The resultant pad temperature profiles, shown in Fig. 14, jumped up by about $30^{\circ} \mathrm{C}$ at the centerline of $z=1.5 \mathrm{~m}$ plane compared with the case of intact lining. This indicates that the low conductivity layers (the thickness of the firebrick and ceramic layers) is one of the key factors that affects the pad temperature distribution.

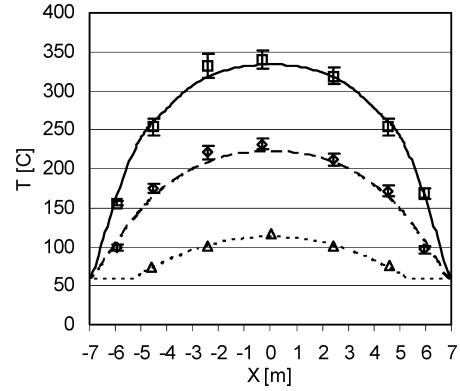

Fig. 14. Temperature profile for the case of removed firebrick layer: $\square, \bigcirc, \triangle$, measured at the levels of $1.5,0.9$ and $0.3 \mathrm{~m}$ respectively;,,$---- \cdots \cdots$, , simulated at the corresponding levels.

Moreover, the predicted temperature profiles appear smoother at each level.

\section{Conclusions}

A three-dimensional computational fluid dynamics model is developed for liquid iron flow and coupled refractory-liquid heat transfer. The model is based on a previous model but with an improved computational mesh quality and mathematical formulation. In particular, the new model has included an extra thermal dispersion term and high order turbulence model to treat the coke bed region and coke free zone consistently. More detailed flow structures and general flow patterns are described. The effects of the coke bed/coke free layer, hearth erosion are investigated for a BF geometry. The simulation results indicate:

(1) Natural convection is very significant and controls the global flow pattern of the melt iron. The sensitivity of calculated flow to the coke free layer is reduced, due to the significant effect of thermally-driven buoyancy flows. This phenomenon helps to further clarify the effect of coke free layer.

(2) A well-organized iron flow patterns is identified: two distinct regions form from the top to the bottom for all six of the coke bed configurations studied. A stagnant flow zone exists in the bottom half of the coke bed above the coke-free layer. The iron temperature varies mainly in vertical direction. These flow and heat transfer behaviours are neither restricted to the particular geometric model, nor the consequence of elaborate formulation of effective conductivity/dispersion, but the predicted results represent the physics in the blast furnace hearth.

(3) The pad temperature distribution becomes less sensitive to the inner conditions of the hearth; rather, it is con- 
trolled significantly by the heat transfer across the hearth refractory, particularly the low thermal conductivity ceramic cup and firebrick. Therefore, the determination of the surface profile and refractory properties under the operating state is critical to the accurate and reliable prediction of the flow and heat transfer in the blast furnace hearth.

It should be pointed out that the current model is limited to a steady-state, single phase flow condition. Further model development is necessary in order to study the transient liquid flow and heat transfer in the entire hearth, including the effects of various other physical and operational factors, such as unsteady tapping and coke bed motion. The current model will provide a basis for this development and the study of these factors.

\section{Acknowledgements}

Financial support from Australian Research Council and BlueScope Steel is gratefully appreciated.

\section{Nomenclature}

$\varepsilon: \quad$ Turbulence dissipation rate $\left(\mathrm{m}^{2} \mathrm{~s}^{-3}\right)$

$\rho$ : Density of fluid $\left(\mathrm{kg} \mathrm{m}^{-3}\right), 7000$ for hot metal and 3000 for slag

$\mu$ : Dynamic viscosity (Pas), $7.15 \times 10^{-3}$

$\mu_{\mathrm{t}}$ : Turbulent viscosity ( $\left.\mathrm{Pa} \mathrm{s}\right)$

$\gamma:$ Porosity of packed bed (-)

$\beta$ : Thermal coefficient of volumetric expansion $\left(\mathrm{K}^{-1}\right), 1.4 \times 10^{-4}$ for hot metal and $7.81 \times 10^{-6}$ for slag

$\phi$ : Shape factor of coke particles

$\left(\lambda_{\text {dis }}\right)_{X X}:$ Apparent conductivity in longitudinal direction

$\left(\lambda_{\text {dis }}\right)_{Y Y}:$ Apparent conductivity in transverse direction

$\lambda_{\mathrm{f}}$ : Thermal conductivity of fluid $\left(\mathrm{W} \mathrm{m}^{-1} \mathrm{~K}^{-1}\right), 16.5$ for hot metal and 1.5 for slag

$\lambda_{\mathrm{s}}$ : Thermal conductivity of solid particle, 2.0 ( $\mathrm{W} \mathrm{m}^{-1} \mathrm{~K}^{-1}$ )

$c_{\mathrm{p}}$ : Specific heat of fluid $\left(\mathrm{J} \mathrm{kg}^{-1} \mathrm{~K}^{-1}\right), 850$ and 1800 for slag

$c_{\mu}:$ Turbulence model constant $(-)$

$d_{\mathrm{p}}$ : Particle size, $0.03(\mathrm{~m})$

$g$ : Gravity, $9.81\left(\mathrm{~m} \mathrm{~s}^{-2}\right)$

$k$ : Turbulence kinetic energy $\left(\mathrm{m}^{2} \mathrm{~s}^{-2}\right)$

$p$ : Pressure $(\mathrm{Pa})$
Pe : $\quad$ Peclet number $\mathrm{Pe}=\frac{\rho c_{\mathrm{p}} d_{\mathrm{p}} \gamma|\mathbf{u}|}{\lambda_{\mathrm{f}}}(-)$

T: $\quad$ Temperature (K)

u : Velocity vector $\left(\mathrm{m} \mathrm{s}^{-1}\right)$

$\sigma_{\mathrm{t}}:$ Turbulent Prandtl number (-)

$\sigma_{\mathrm{T}}:$ Turbulent Prandtl number for enthalpy (-)

$\delta$ : Unit tensor

\section{REFERENCES}

1) T. Fukutake and K. Okabe: Trans. Iron Steel Inst. Jpn., 16 (1976), 309.

2) A. Shinotake, M. Ichida, H. Ootsuka and Y. Sugizaki: Tetsu-toHagané, 87 (2001), 388.

3) K. Takatani, T. Inada and K. Takata: ISIJ Int., 41 (2001), 1139.

4) Y. Li, Y. Q. Li and J. Fruehan: ISIJ Int., 41 (2001) 1417.

5) F. Yoshikawa and J. Szekely: Ironmaking Steelmaking, 8 (1981), 159.

6) K. Shibata, Y. Kimura, M. Shimizu and S. Inaba: ISIJ Int., 30 (1990), 208

7) A. Preuer, J. Winter and H. Hiebler: Steel Res., 63 (1992), 139, 147.

8) K. Kurita and A. Ogawa: Proc. 1st Int. Cong. on Science and Technology of Ironmaking, ISIJ, Tokyo, Japan, (1994), 284.

9) W. Kowalski, H. H. Bachhofen, H. P. Ruther, S. Rodl, K. Marx and T. Thiemann: ISS Ironmaking Conf. Proc., 57 (1998), 595.

10) K. Raipala: Scand. J. Metall., 29 (2000), 39.

11) J. Torrkulla and H. Saxen: ISIJ Int., 40 (2000), 438.

12) S. Kumar: ISIJ Int., 45 (2005), 1122.

13) K. Nishioka, T. Maeda and M Shimizu: ISIJ Int., 45 (2005), 669.

14) T. Nouchi, M. Yasui and K. Takeda: ISIJ Int., 43 (2003), 175.

15) K. Nishoka, T. Maeda and M. Shimizu: ISIJ Int., 45 (2005), 1496.

16) V. Panjkovic, J. S. Truelove and P. Zulli: Ironmaking Steelmaking, 29 (2002), 390.

17) A. Nakayama and F. Kuwahara: J. Fluids Eng., 121 (1999), 427.

18) B. Y. Guo, A. B. Yu, B. Wright and P. Zulli: Chem. Eng. J., 29 (2006), 596.

19) A. Nakayama and F. Kuwahara: Handbook of Porous Media, ed. by K. Vafai, Marcel Dekker, Inc., New York, (2000), 441.

20) F. Kuwahara and A. Nakayama: J. Heat Transfer, 121 (1999), 160.

21) C. Jayatilleke: Prog. Heat Mass Transfer, 1 (1969), 193.

22) J. R. Post, T. Peeters, Y. Yang and M. A. Reuter: 3rd Int. Conf. on CFD in Mineral and Process Industries, CSIRO, Melbourne, Australia, (2003), 433.

23) A. Preuer, J. Winter and H. Hiebler: Steel Res., 63 (1992), 139.

24) S. Watakabe, K. Takeda, Y. Sawa and T. I. Kawai: Tetsu-to-Hagané, 86 (2000), 301.

25) N. Saito, N. Hori, K. Nakashima and K. Mori: Metall. Mater. Trans. $B$, 34B (2003), 509.

26) S. Inaba, Y. Kimura, H. Shibata and H. Oh: ISIJ Int., 44 (2004), 2120 . 